\title{
Acetylcholine and bradykinin enhance hypotension and affect the function of remodeled conduit arteries in SHR and SHR treated with nitric oxide donors
}

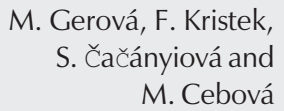

Institute of Normal and Pathological Physiology, Slovak Academy of Sciences, Bratislava, Slovakia

\section{Correspondence}

M. Gerová

Institute of Normal and

Pathological Physiology

Slovak Academy of Sciences

Sienkiewiczova 1, 81371

Bratislava

Slovakia

E-mail: maria.gerova@savba.sk

Research supported by VEGA (Nos. 2/7240/21, 2/7241/20). ...................

Received May 7, 2004 Accepted February 21, 2005

\begin{abstract}
Discrepancy was found between enhanced hypotension and attenuated relaxation of conduit arteries in response to acetylcholine (ACh) and bradykinin (BK) in nitric oxide (NO)-deficient hypertension. The question is whether a similar phenomenon occurs in spontaneously hypertensive rats (SHR) with a different pathogenesis. Wistar rats, SHR, and SHR treated with NO donors [molsidomine $(50 \mathrm{mg} / \mathrm{kg})$ or pentaerythritol tetranitrate $(100 \mathrm{mg} / \mathrm{kg})$, twice a day, by gavage] were studied. After 6 weeks of treatment systolic blood pressure (BP) was increased significantly in experimental groups. Under anesthesia, the carotid artery was cannulated for BP recording and the jugular vein for drug administration. The iliac artery was used for in vitro studies and determination of geometry. Compared to control, SHR showed a significantly enhanced $(\mathrm{P}<0.01)$ hypotensive response to $\mathrm{ACh}(1$ and $10 \mu \mathrm{g}, 87.9 \pm 6.9$ and $108.1 \pm 5.1$ vs $35.9 \pm 4.7$ and $64.0 \pm 3.3 \mathrm{mmHg})$, and $\mathrm{BK}(100 \mu \mathrm{g}, 106.7$ \pm 8.3 vs $53.3 \pm 5.2 \mathrm{mmHg}$ ). SHR receiving NO donors yielded similar results. In contrast, maximum relaxation of the iliac artery in response to ACh was attenuated in SHR (12.1 \pm 3.6 vs $74.2 \pm 8.6 \%$ in controls, $\mathrm{P}<0.01)$. Iliac artery inner diameter also increased $(680 \pm$ 46 vs $828 \pm 28 \mu \mathrm{m}$ in controls, $\mathrm{P}<0.01)$. Wall thickness, wall crosssection area, wall thickness/inner diameter ratio increased significantly $(\mathrm{P}<0.01)$. No differences were found in this respect among SHR and SHR treated with NO donors. These findings demonstrated enhanced hypotension and attenuated relaxation of the conduit artery in response to NO activators in SHR and in SHR treated with NO donors, a response similar to that found in NOdeficient hypertension.
\end{abstract}

\section{Introduction}

After inhibition of nitric oxide synthase (NO synthase), there is a clear discrepancy in experimental results concerning the acetyl-
Key words

- Hypertension

- Conduit iliac artery

- Resistance arteries

- Molsidomine

- Pentaerythritol tetranitrate

- Iliac artery

- Structure 
tenuation up to total inhibition of relaxation in response to ACh when applied after NO synthase inhibition (1-3). Even NO release, measured directly close to the endothelial layer in the femoral artery of the dog, decreased after NO synthase inhibition (4). In contrast, experiments performed on conscious animals, animals under anesthesia, and moreover, under various types of anesthesia, with NO synthase inhibition and consequent increased blood pressure, have demonstrated hypotension elicited by ACh (5-7). Previous studies by our group showed paradoxically amplified ACh hypotension not only after a short period of time (1-2 h) but also 6 weeks after NO synthase inhibition, which was accompanied by sustained high blood pressure (8). The amplified hypotension was triggered via muscarinic receptors. However, bradykinin, another activator of $\mathrm{NO}$ synthase, also induced hypotension after $\mathrm{NO}$ synthase inhibition accompanied by hypertension (8).

Substitution of endogenous NO in NOcompromised hypertensive rats with exogenous NO, released from NO donors, only partially reduced the systemic high blood pressure $(9,10)$. However, the enhanced response to ACh and bradykinin in these animals was unchanged after molsidomine treatment.

The question addressed here was: does the discrepancy between blood pressure response to ACh and bradykinin observed in in vivo experiments and in isolated vessels in vitro also occur in another model of experimental hypertension? The model of spontaneously hypertensive rats (SHR) was selected to test this issue. The reason for studying SHR was that there are data indicating that compromised NO production is very probably not the essential etiopathogenic cause of hypertension in these animals (1113). On the other hand, it is important to keep in mind that Pourageaud and Freslon (14) and Liu et al. (15), on the basis of their experiments with SHR, reported compro- mised function of endothelial cells.

The hypotensive response to $\mathrm{ACh}$ and bradykinin in both experimental models, NOdeficient hypertensive rats and SHR, is the result of relaxation of resistance arteries. Indeed, the efficiency of heart work (assessed by left ventricular $\mathrm{dP} / \mathrm{dt}_{\max }$ and left ventricular $\mathrm{dP} / \mathrm{dt}_{\min }$ ) in NO-defective hypertensive animals did not differ from control animals (16). The same was true for SHR (17-19).

The response to ACh of the common iliac artery, as a representative of the conduit portion, was studied in vitro in SHR. The geometry of the conduit iliac artery was studied as a morphological background for vessel responses.

The effect of individual NO donors on blood pressure in various experimental hypertensive models is not unequivocal (9). Two NO donors, molsidomine and pentaerythritol tetranitrate (PETN), were selected because they do not induce a tolerance effect $(20,21)$. Moreover, PETN has been shown to have antioxidant properties (22).

\section{Material and Methods}

The experiments were carried out in male rats housed in individual cages at a temperature of $22-24^{\circ} \mathrm{C}$, under a 12 -h light/dark cycle. The animals were fed a standard pellet diet and had free access to water. The procedures were approved by the Ethics Committee for Experimental Studies, Slovak Academy of Sciences.

The animals, 10 weeks of age at the beginning of the study, were divided into the following groups:

Group I: control Wistar rats, 16 animals living for 6 weeks under the above standard housing conditions without any medication. Group II: 16 SHR housed for 6 weeks as group I without receiving any medication. Group III: 16 SHR receiving molsidomine, $50 \mathrm{mg} / \mathrm{kg}$ twice a day by gavage, for 6 weeks. Group IV: 16 SHR receiving PETN, 
$100 \mathrm{mg} / \mathrm{kg}$ twice a day by gavage for 6 weeks.

In all groups systolic blood pressure was measured noninvasively in pre-warmed rats by the tail plethysmography method once a week.

\section{In vivo studies}

At the end of the experiments, half the animals in each group $(\mathrm{N}=8)$ were anesthetized $i p$ with sodium pentobarbital, $50 \mathrm{mg} / \mathrm{kg}$ body weight, for vessel preparation and cannula implantation. The right jugular vein was prepared and cannulated. Heparin sulfate (25 IU) was administered immediately and the right carotid artery was prepared, cannulated and connected to a Statham P32 Db pressure transducer. A Physioscript Schwarzer device was used for blood pressure recording. Immediately after this procedure, one third of the first dose of pentobarbital sodium was administered ip. During the next $15 \mathrm{~min}$, on the basis of the recorded blood pressure, steady state was achieved and ACh (1 and 10 $\mu \mathrm{g})$ and bradykinin $(100 \mu \mathrm{g})$, each dissolved in $0.1 \mathrm{ml} \mathrm{Krebs} \mathrm{solution,} \mathrm{were} \mathrm{administered}$ into the jugular vein in random order. A constant 10-s period of $i v$ administration was used. At the end of the experiment the animals were sacrificed with an overdose of pentobarbital sodium.

\section{Morphological studies}

The other half of the animals in each group were anesthetized with pentobarbital sodium, $50 \mathrm{mg} / \mathrm{kg}$, administered ip. After opening the abdomen, the left iliac artery of groups I and II was isolated, excised, placed in the cold Krebs solution, and prepared for the in vitro experiments. The chest was then opened, a cannula was placed inside the left ventricle and the cardiovascular system was perfused at a constant pressure of $120 \mathrm{mmHg}$ for 10 min with a fixative consisting of 300 $\mathrm{mM}$ glutaraldehyde in $100 \mathrm{mM}$ phosphate buffer. The upper part of the right iliac artery was excised, immersed in the same fixative, divided into four segments, and post-fixed with $40 \mathrm{mM} \mathrm{OsO}_{4}$ in phosphate buffer. After fixation the samples were stained en bloc with uranyl acetate, dehydrated in a growing alcohol series, and embedded in Durcupan ACM. Three randomly selected blocks from each artery were cut perpendicularly to the long axis. Both inner circumference and arterial wall thickness (tunica intima and tunica media) were measured by light microscopy. The arterial wall thickness was measured around the vessel circumference at about $45^{\circ}$ intervals. The inner diameter and the cross-sectional area (tunica intima and tunica media) were calculated.

\section{In vitro studies}

The left common iliac arteries were cleaned of adherent connective tissue and cut into 34-mm long rings. The rings were fixed vertically between two stainless steel wires in an incubation bath with oxygenated Krebs solution $\left(95 \% \mathrm{O}_{2}\right.$ and $\left.5 \% \mathrm{CO}_{2}\right)$ and kept at $37^{\circ} \mathrm{C}$.

The arterial rings were connected to a force transducer (Sanborn FTA 10) to record the changes in isometric tension, as described earlier (3). Resting tension was adjusted to $10 \mathrm{mN}$ and the preparations were allowed to equilibrate for 60-90 min. Endothelium-dependent relaxations were studied in rings with a functional endothelium and precontracted to the maximal response induced by phenylephrine $(10 \mu \mathrm{M})$. Acetylcholine was applied in a cumulative fashion and relaxation was reported as percentage of phenylephrine-induced contraction.

\section{Chemicals}

Molsidomine was purchased from Hoechst (Frankfurt, Germany), and pentaerythritol tetranitrate from Dipharma (Milano, Italy). 
The composition of the Krebs solution was $118 \mathrm{mM} \mathrm{NaCl}, 5 \mathrm{mM} \mathrm{KCl}, 25 \mathrm{mM}$ $\mathrm{NaHCO}_{3}, 1.2 \mathrm{mM} \mathrm{MgSO}_{4}, 1.2 \mathrm{mM} \mathrm{KH}_{2} \mathrm{PO}_{4}$, $2.5 \mathrm{mM} \mathrm{CaCl}_{2}, 11 \mathrm{mM}$ glucose, $1.1 \mathrm{mM}$ ascorbic acid, and $32 \mu \mathrm{M} \mathrm{CaNa}{ }_{2}$ EDTA.

\section{Statistical analysis}

Data are reported as means \pm SEM. ANOVA and the Bonferroni test for unpaired variables were used for statistical evaluation. Results were considered significant when $\mathrm{P}$ $<0.05$.

\section{Results}

\section{In vivo studies}

After 6 weeks of the experimental regime, mean systolic blood pressure was $132.5 \pm 2.7 \mathrm{mmHg}$ for the control group, $177.1 \pm 5.4 \mathrm{mmHg}$ for SHR $(\mathrm{P}<0.01 v s$

Figure 1. Decrease of diastolic blood pressure elicited by iv administration of 1 and $10 \mu \mathrm{g}$ acetylcholine (A) or $100 \mu \mathrm{g}$ bradykinin (B), in $0.1 \mathrm{ml}$ Krebs solution, over a period of $10 \mathrm{~s}$. Control Wistar rats (white columns), spontaneously hypertensive rats (SHR, light gray columns), SHR treated with molsidomine (gray columns), and SHR treated with pentaerythritol tetranitrate (striped columns). Data are reported as means \pm SEM for 8 rats in each group. Rats were treated with molsidomine or pentaerythritol as described in the legend to Table 1. ${ }^{*} P<0.01$ compared to control (ANOVA and Bonferroni test for unpaired variables).

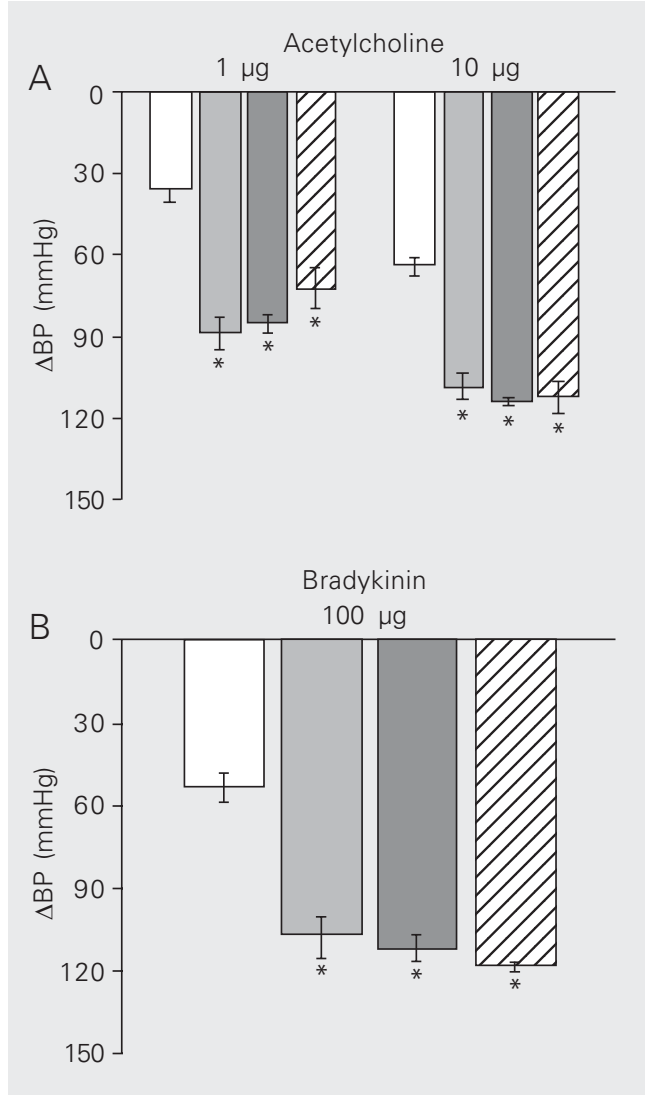

controls), $175.2 \pm 2.8 \mathrm{mmHg}$ for SHR treated with molsidomine ( $\mathrm{P}<0.01$ vs controls), and $176.6 \pm 5.7 \mathrm{mmHg}$ for SHR treated with PETN ( $\mathrm{P}<0.01$ vs controls). No change in blood pressure occurred in SHR after 6 weeks of molsidomine or PETN administration.

A significant increase in the heart/body weight ratio was observed for all three experimental groups compared to control (3.13 $\left.\pm 0.03 \times 10^{-3}\right)$, i.e., $4.91 \pm 0.18 \times 10^{-3}$ for SHR $(\mathrm{P}<0.01), 3.77 \pm 0.08 \times 10^{-3}$ for SHR + molsidomine $(\mathrm{P}<0.05)$, and $4.45 \pm 0.03 \mathrm{x}$ $10^{-3}$ for SHR + PETN $(\mathrm{P}<0.01)$.

The range of hypotensive responses (reported as diastolic blood pressure) to $i v$ administration of ACh in two doses of 1 and $10 \mu \mathrm{g}$ for the individual groups is illustrated in Figure 1A. The following mean values in response to the 1 - and $10-\mu \mathrm{g}$ dose were obtained: $35.9 \pm 4.7$ and $64.0 \pm 3.3 \mathrm{mmHg}$, respectively, for the control group, $87.9 \pm$ $6.9 \mathrm{mmHg}(\mathrm{P}<0.01)$ and $108.1 \pm 5.1 \mathrm{mmHg}$ $(\mathrm{P}<0.01)$, respectively, for the SHR group, with both values showing a significant increase. The values were $85.4 \pm 2.6$ and 113.5 $\pm 1.4 \mathrm{mmHg}(\mathrm{P}<0.01)$ for the SHR group treated with molsidomine and $73.0 \pm 6.3$ $\mathrm{mmHg}(\mathrm{P}<0.01)$ and $111.7 \pm 5.9 \mathrm{mmHg}(\mathrm{P}$ $<0.01)$ for the SHR group treated with PETN. No significant differences in the extent of hypotension were found between the SHR group, the SHR group treated with molsidomine and the SHR group treated with PETN in response to either dose.

The hypotensive response to iv bradykinin at the dose of $100 \mu \mathrm{g}$ was $53.3 \pm 5.2$ $\mathrm{mmHg}$ for controls and was significantly increased to $106.7 \pm 8.3 \mathrm{mmHg}$ in SHR $(\mathrm{P}<$ $0.01)$. Similarly, the response was $111.6 \pm$ $4.8 \mathrm{mmHg}$ in SHR treated with molsidomine $(\mathrm{P}<0.01)$ and $118.3 \pm 1.8 \mathrm{mmHg}$ in SHR treated with PETN $(\mathrm{P}<0.01)$. No significant difference in bradykinin hypotension was found between the SHR group and the two SHR groups treated with either molsidomine or PETN (Figure 1B). 


\section{In vitro studies}

Plots of the isometric tension of iliac artery rings and doses of $\mathrm{ACh}$ are illustrated in Figure 2. Maximum relaxation in response to ACh was $74.24 \pm 8.57 \%$ of phenylephrine precontraction $(10 \mu \mathrm{M})$ in iliac artery rings from control Wistar rats. In contrast, iliac artery rings from SHR showed a clear-cut attenuated relaxation in the whole range of $\mathrm{ACh}$ doses used. The maximum value represented only $12.14 \pm 3.6 \%(\mathrm{P}<0.01)$ of the phenylephrine precontraction described above.

\section{Morphological studies}

The individual parameters characterizing the geometry of the iliac artery are given in Table 1 . The wall thickness of the iliac artery was significantly greater in all experimental groups compared to control. No significant differences in this parameter were found between SHR, SHR + molsidomine and SHR + PETN

The cross-sectional area of the arterial wall (tunica intima + tunica media) was significantly and similarly enlarged in the SHR group, in the SHR + molsidomine group, and in the SHR + PETN group.

The inner diameter of the iliac artery was significantly and similarly reduced in the SHR, SHR + molsidomine, and SHR + PETN groups compared to control Wistar rats.

The calculated wall thickness/inner diameter ratio was significantly and similarly increased in the SHR group, SHR + molsidomine group, and in the SHR + PETN group compared with control Wistar rats.

\section{Discussion}

Systolic blood pressure, remarkably higher in SHR than in Wistar rats, continued to be high even after 6 weeks of treatment with the exogenous NO donors molsidomine or PETN. The results confirmed the view that $\mathrm{NO}$ and/ or compromised NO production very probably was not the essential etiopathogenic factor in this model of experimental hypertension, in agreement with data reported by others (11-13). On the basis of the convincing experimental results of Matsumoto (23), Head (24) and Korner et al. (25), it appears that the sympathetic nervous system, to-

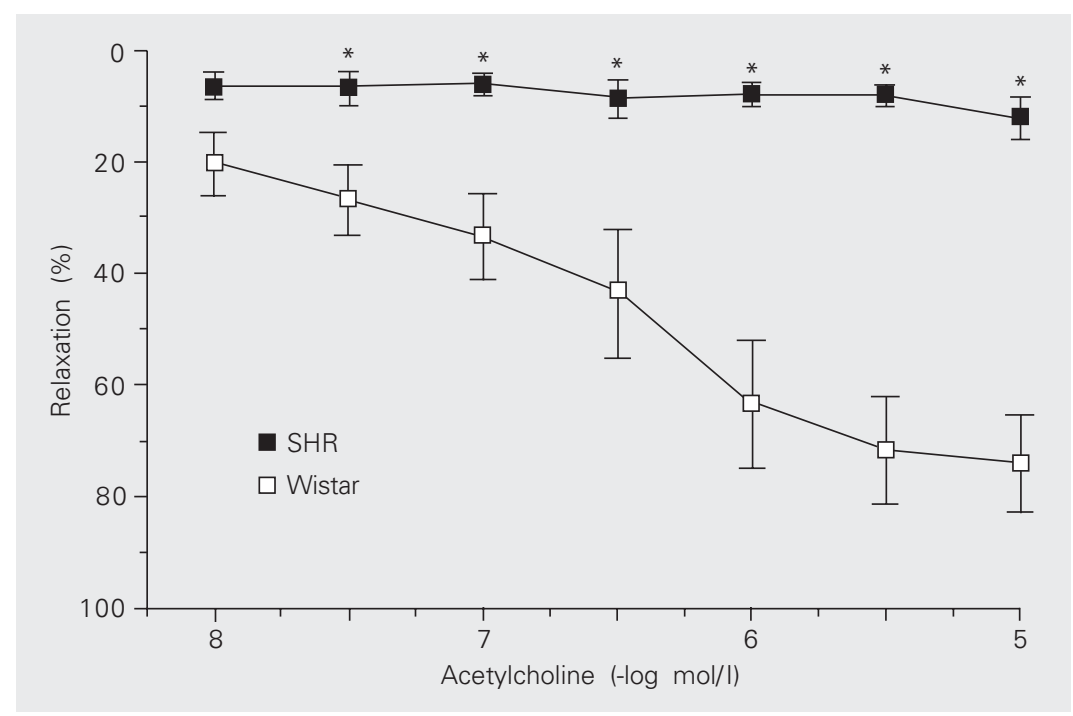

Figure 2. Endothelium-dependent relaxation of the conduit iliac artery of control Wistar rats (open squares) and spontaneously hypertensive rats (SHR, full squares) evoked by increasing doses of acetylcholine. Relaxation is reported as percentage of isometric tension induced by $10 \mu \mathrm{M}$ phenylephrine in precontracted iliac artery. Data are reported as means \pm SEM for 8 rats in each group. ${ }^{*} \mathrm{P}<0.01$ compared to control (ANOVA and Bonferroni test for unpaired variables).

Table 1. Effect of molsidomine and pentaerythritol on the geometry of the common iliac artery of spontaneously hypertensive rats (SHR).

\begin{tabular}{lcccl}
\hline & WT $(\mu \mathrm{m})$ & CSA $\times 10^{3}\left(\mu \mathrm{m}^{2}\right)$ & ID $(\mu \mathrm{m})$ & WT/ID $\times 10^{-2}$ \\
\hline Control & $28.99 \pm 2.09$ & $77.27 \pm 4.64$ & $828 \pm 28$ & $3.59 \pm 0.36$ \\
SHR & $54.12 \pm 2.00^{*}$ & $123.00 \pm 6.30^{*}$ & $680 \pm 46^{*}$ & $8.65 \pm 0.91^{*}$ \\
SHR + MOLS & $57.09 \pm 2.90^{*}$ & $123.00 \pm 5.90^{*}$ & $630 \pm 16^{*}$ & $9.13 \pm 0.60^{*}$ \\
SHR + PETN & $53.78 \pm 2.85^{*}$ & $110.00 \pm 4.50^{*}$ & $601 \pm 16^{*}$ & $9.06 \pm 0.69^{*}$ \\
\hline
\end{tabular}

The rats received $50 \mathrm{mg} / \mathrm{kg}$ twice a day molsidomine (MOLS) and $100 \mathrm{mg} / \mathrm{kg}$ twice a day pentaerythritol tetranitrate (PETN), by gavage for 6 weeks. The artery was perfused with glutaraldehyde at $120 \mathrm{mmHg}$ pressure. Data are reported as means \pm SEM for 8 rats in each group. WT = wall thickness in $\mu \mathrm{m}$ (tunica intima + tunica media); CSA $=$ cross-section area of the wall in $\mu m^{2} \times 10^{3}$ (tunica intima + tunica media); ID = inner diameter of the iliac artery in $\mu \mathrm{m} ; \mathrm{WT} / \mathrm{ID}=$ wall thickness/inner diameter ratio.

${ }^{*} \mathrm{P}<0.01$ compared to the control group (ANOVA and Bonferroni test for unpaired variables) 
gether with the renin-angiotensin system, constitute one of the essential causes of high blood pressure in SHR.

The question raised in the Introduction was to compare the range of hypotension in SHR and the range of isometric tension of the conduit iliac artery induced by ACh and bradykinin - two activators involved in $\mathrm{NO}$ production. In SHR, the experiments unequivocally demonstrated a remarkably enhanced dose-dependent hypotension in response to ACh and to bradykinin compared to Wistar rats. Two components contribute to the hypotension induced by ACh: cardiac efficiency and the tonus of resistance arteries. Reliable experimental data have shown that cardiac efficiency is not compromised in SHR in steady state between 10 and 20 weeks of age (17-19). Moreover, Mertens et al. (26) demonstrated that the density of muscarinic receptors in the cardiomyocytes of SHR is unchanged and the contractile force of the myocardium after methacholine is high enough and thus could not explain the increased hypotension.

We were also interested in the behavior of the resistance arteries. If the response of resistance vessels of SHR to ACh and bradykinin were attenuated as in the conduit iliac artery, the extent of hypotension could not be larger. It should be kept in mind that the decrease in blood pressure is an integrated response of resistance arteries in individual areas. Granstam et al. (27) did not find changes in blood flow in the heart and kidney of SHR after ACh, whereas Chang et al. (28), using the perfusion technique to study the response of the mesenteric vascular response to ACh in SHR, found an amplification of the hypotensive response. In the present study, the enhanced extent of hypotension in SHR did not change after administration of molsidomine or PETN. The present findings are similar to those obtained in NO-deficient hypertension $(6,8)$ although the etiopathogenic background, $\mathrm{NO}$ production, $\mathrm{NO}$ level, and cGMP level are different in these two experimental models of hypertension (29).

The enhanced ACh- and bradykinin-induced hypotension in both experimental models, i.e., NO-compromised hypertensive rats and SHR, suggests that NO is very probably not involved in this phenomenon. Thus, it is reasonable to propose that $\mathrm{ACh}$ and bradykinin trigger a completely different mechanism of vascular smooth muscle relaxation in resistance vessels, with consequent hypotension.

Contrary to the enhanced hypotension, the response of the isolated conduit iliac artery of SHR to ACh was remarkably attenuated, in agreement with the attenuated responses to $\mathrm{ACh}$ and bradykinin by other conduit arteries from SHR in vitro $(14,30)$. Moreover, a similar attenuation of ACh relaxation was also reported in vitro in conduit artery segments from NO-compromised hypertensive rats (1-3). Thus, the clear-cut discrepancy in the response to the NO synthase activators $\mathrm{ACh}$ and bradykinin between resistance arteries and conduit arteries is present in SHR as well as in NO-compromised hypertensive rats.

The cause underlying the different responses of smooth muscle cells in conduit and resistance arteries can be considered in terms of the following: there is a downward gradient of endothelial NO synthase expression from the aorta to resistance arteries and capillaries (31-33), and ACh might affect the activity of NO synthase in large conduit vessels. Malinski et al. (34) and Pourageaud and Freslon (14) reported compromised NO production in endothelial cells of the aorta or coronary artery of SHR. Thus, the attenuated relaxation of the iliac conduit artery in response to $\mathrm{ACh}$ is possible.

What relaxing mechanisms triggered by $\mathrm{ACh}$ and bradykinin could operate in the resistance portion of the arterial tree? Hypothetically, the involvement of endotheliumderived hyperpolarizing factor and of potassium channel function could be considered in view of the fact that their effectiveness is not 
influenced by high blood pressure (35).

An increase of wall thickness was found in the iliac artery and was consistent with that of the aorta, carotid artery and septal branch of the coronary artery both in SHR and in SHR treated with molsidomine or PETN (36). However, concerning the inner diameter of the iliac artery, completely different values were found in comparison with the thoracic aorta, carotid artery, and coronary artery in SHR. The inner diameter of the iliac artery decreased significantly in SHR, but this was not the case for the diameter of the aorta, carotid artery, and coronary artery (36). The decrease of the inner diameter was not affected by either molsidomine or PETN .

The decrease of the inner diameter of the iliac artery could be understood on the basis of two factors. One concerns the dominant role of the sympathetic nervous system supported by the RAS in maintaining the high blood pressure in SHR (23-25). The second concerns the paradigm that the effect of sympathetic control increases downwards along the arterial tree. Evidence has also been provided for the conduit portion of the arterial tree, including the abdominal aorta (37). The magnitude of maximum constriction of the abdominal aorta induced by supramaximal stimulation of the respective sympathetic postganglionic fibers increases gradually from the upper part of the abdominal aorta, above the renal branching, down- wards to the iliac bifurcation, and very probably consecutively downwards to the iliac artery. Considering the two issues, the narrowing of the iliac arteries in SHR, in comparison with the proximal portions of the arterial tree, is conceivable. The wall thickness and wall thickness/inner diameter ratio are typical characteristics of conduit arteries in hypertension and are consistent with the attenuated response to $\mathrm{ACh}$ and bradykinin observed in vitro.

In conclusion, in SHR, ACh and bradykinin as NO synthase activators induced a dose-dependent enhanced hypotensive response. However, the conduit iliac artery relaxation in vitro in response to ACh was attenuated. These findings are similar to those obtained in NO-deficient hypertension. The thickness of the iliac artery wall increased and its inner diameter decreased. The discrepancy between these two functional parameters leads us to conclude that two different mechanisms are induced by ACh and bradykinin in resistance and conduit arteries in both experimental models of hypertension.

\section{Acknowledgments}

The authors wish to thank Anna Buzalková for technical assistance and Katarína Šoltésová for library and secretarial work.

\section{References}

1. Rees DD, Palmer RHJ, Schulz R, Hodson HF \& Moncada S (1990). Characterization of three inhibitors of endothelial nitric oxide synthase in vitro and in vivo. British Journal of Pharmacology, 101: 746752.

2. Hwa JJ, Ghibaudi L, Williams P \& Chatterjee M (1994). Comparison of acetylcholine-dependent relaxation in large and small arteries of rat mesenteric vascular bed. American Journal of Physiology, 266: H952-H958

3. Török J \& Kristek F (2002). Beneficial effect of pentaerythritol tetranitrate on functional and morphological changes in the rat thoracic aorta evoked by long-term nitric oxide synthase inhibition. Vascular Pharmacology, 38: 177-182.
4. Gerová M, Mesároš Š, Kristek F, Kittová M \& Malinski T (1998). NO concentration in the periendothelial area of the femoral artery of the dog measured in vivo. Physiological Research, 47: 169-175.

5. Gardiner SM, Compton AM, Kemp PA \& Bennett T (1990). Regional and cardiac haemodynamic responses to glyceryl trinitrate, acetylcholine, bradykinin and endothelin-1 in conscious rats: effects of $N^{G}$-nitro-L-arginine methyl ester. British Journal of Pharmacology, 101: 632-639.

6. Zanchi A, Aubert JF, Brunner HR \& Waeber B (1995). Vascular acetylcholine response during chronic NO synthase inhibition: in vivo versus in vitro. Cardiovascular Research, 30: 122-129.

7. Kakizoe E, Wang D-Q, Kobayashi Y, Shimoura K \& Okunishi H 
(1998). Acetylcholine-induced systemic vasodilation resistance to $\mathrm{NG}_{\text {-nitro-L-arginine in anesthetized rats. Clinical and Experimental }}$ Pharmacology and Physiology, 25: 510-516.

8. Gerová M (1999). Acetylcholine and bradykinin induce paradoxically amplified hypotensive response in hypertensive NO-deficient rats. Physiological Research, 48: 249-257.

9. Gerová M \& Kristek F (2001). Efficiency of NO donors in substituting the impaired endogeous NO production. Functional and morphological study. Physiological Research, 50: 165-173.

10. Kristek $F$ (2000). Pentaerythritol tetranitrate could prevent structural changes in conduit arteries evoked by long-term NO-synthase inhibition. British Journal of Pharmacology, 130: 450-456.

11. Fozard JR \& Part M-L (1991). Haemodynamic responses to NG monomethyl-L-arginine in spontaneously hypertensive and normotensive Wistar-Kyoto rats. British Journal of Pharmacology, 102: 823-826.

12. Arnal J-F, Battle T, Ménard J \& Michel J-B (1993). The vasodilatory effect of endogenous nitric oxide is a major counter-regulatory mechanism in the spontaneously hypertensive rat. Journal of Hypertension, 11: 945-950.

13. Kristek $F$ (1998). Long-term administration of L-arginine did not influence blood pressure, heart rate, cardiac hypertrophy or arterial wall thickness of spontaneously hypertensive rats. Experimental Physiology, 83: 595-603.

14. Pourageaud F \& Freslon J-L (1995). Impaired endothelial relaxations induced by agonists and flow in spontaneously hypertensive rat compared to Wistar-Kyoto rat perfused coronary arteries. Journal of Vascular Research, 32: 190-199.

15. Liu H, Ledingham JM, Mullaney I \& Laserty R (2002). Endothelial function in mesenteric resistance arteries from genetically hypertensive rat. Clinical and Experimental Pharmacology and Physiology, 29: 405-411.

16. Ravingerová $T$, Šimončíková $P$, Strnisková $M$, Barančík $M$, Ziegelhoffer A \& Gerová M (2003). Tolerance to cardiac ischemia/ reperfusion injury is modulated in hypertensive rats with chronic NO deficiency. Experimental and Clinical Cardiology, 8: 47 (Abstract).

17. Albrecht I (1974). The hemodynamics of early stages of spontaneous hypertension in rats. Japanese Circulation Journal, 38: 985990.

18. Smith TL \& Hutchins PM (1979). Central hemodynamics in the developmental stage of spontaneous hypertension in the anesthetized rat. Hypertension, 1: 508-517.

19. Yamamoto J, Nakai M \& Natsume T (1987). Cardiovascular responses to acute stress in young-to-old spontaneously hypertensive rats. Hypertension, 9: 362-370.

20. Dück KD \& Richard F (1990). Langzeitnitrattherapie bei koronarer Herzkrankheit - Wirkungsverlust durch Toleranzentwicklung? (Longterm therapy of coronary artery disease - loss of efficacy through development of tolerance?). Zeitschrift für die Gesamte Innere Medizin, 24: 736-741.

21. Fink B \& Bassenge E (1997). Unexpected, tolerance-devoid vasomotor and platelet actions of pentaerythritol tetranitrate. Journal of Cardiovascular Pharmacology, 30: 831-836.

22. Oberle S, Schwartz P, Abate A \& Schroder H (1999). The antioxi- dant defense protein ferritin is a novel and specific target for pentaerythritol tetranitrate in endothelial cells. Biochemical and Biophysical Research Communications, 261: 28-34.

23. Matsumoto M (1969). Morphological studies on the nervous system of spontaneously hypertensive rat. Fluorescence microscopical observations on the superior cervical sympathetic ganglia of SHR. Japanese Circulation Journal, 33: 411-416.

24. Head RJ (1989). Hypernoradrenergic innervation: its relationship to functional and hyperplastic changes in the vasculature of the spontaneously hypertensive rat. Blood Vessels, 26: 1-20.

25. Korner P, Bobik A, Oddie C \& Friberg P (1993). Sympathoadrenal system is critical for structural changes in genetic hypertension. Hypertension, 22: 243-252.

26. Mertens MJ, Batink HD, Mathy MJ, Pfaffendorn M \& van Zwieten PA (1995). Reduced muscarinic cholinoceptor density and sensitivity in various models of experimental cardiac hypertrophy. Journal of Autonomic Pharmacology, 15: 465-474.

27. Granstam SO, Granstam E, Follstrom B \& Lind L (1998). Effects of acetylcholine and nitroprusside on systemic and regional hemodynamics in hypertensive rats. Clinical and Experimental Hypertension, 20: 223-243.

28. Chang HR, Lee RP, Wu CY \& Chen HI (2002). Nitric oxide in mesenteric vascular reactivity: a comparison between rats with normotension and hypertension. Clinical and Experimental Pharmacology and Physiology, 29: 275-280.

29. Qiu HY, Henrion D, Benessiano J, Heymes C, Tournier B \& Levy BI (1998). Decreased flow-induced dilation and increased production of cGMP in spontaneously hypertensive rats. Hypertension, 32: 1098-1103

30. Mayhan WG (1990). Impairment of endothelium-dependent dilatation of basilar artery during chronic hypertension. American Journal of Physiology, 259: H1455-H1462.

31. Addicks K, Bloch W \& Feelisch M (1994). Nitric oxide modulates sympathetic neurotransmission at the prejunctional level. Microscopy Research and Technique, 29: 161-168.

32. Laughlin MH, Turk JR, Schrage WG, Woodman CR \& Price EM (2003). Influence of coronary artery diameter on eNOS protein content. American Journal of Physiology, 284: H1307-H1312.

33. Kimura C, Oike M, Ohnaka K, Nosey Y \& Ito Y (2004). Constitutive nitric oxide production in bovine aortic and brain microvascular endothelial cells: a comparative study. Journal of Physiology, 554: 721-730.

34. Malinski T, Kapturczak M, Dayharsh J \& Bohr D (1993). Nitric oxide synthase activity in genetic hypertension. Biochemical and Biophysical Research Communications, 194: 654-658.

35. Feletou M \& Vanhoutte PM (2000). Endothelium-dependent hyperpolarization of vascular smooth muscle cells. Acta Pharmacologica Sinica, 21: 1-18.

36. Kristek F, Fáberová V \& Varga I (2003). Long-term effect of molsidomine and pentaerythritol tetranitrate on cardiovascular system of spontaneously hypertensive rats. Physiological Research, 52: $709-717$.

37. Gerová M, Gero J, Doležel S \& Blažková-Huzuláková I (1973). Sympathetic control of canine abdominal aorta. Circulation Research, 33: 149-159. 